\title{
Skin conductance measurement for the assessment of analgosedation adequacy in infants treated with mechanical ventilation: A multicenter pilot study
}

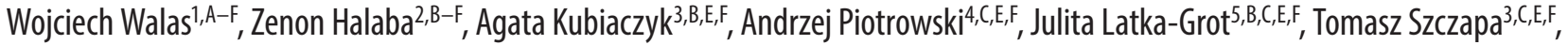

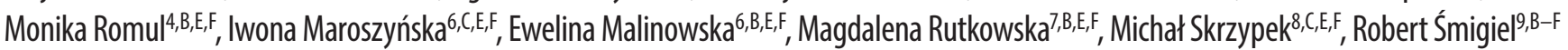 \\ ${ }^{1}$ Pediatric and Neonatal Intensive Care Unit, University Hospital in Opole, Poland \\ ${ }^{2}$ Department of Pediatrics, Institute of Medical Sciences, University of Opole, Poland \\ ${ }^{3}$ Department of Neonatology, Neonatal Biophysical Monitoring and Cardiopulmonary Therapies Research Unit, Poznań University of Medical Sciences, Poland \\ ${ }^{4}$ Department of Anesthesiology and Intensive Care, Children's Memorial Health Institute, Warszawa, Poland \\ ${ }^{5}$ Neonatal Department, Children's Memorial Health Institute, Warszawa, Poland \\ ${ }^{6}$ Department of Intensive Care and Congenital Malformations of Newborns and Infants, Polish Mother's Memorial Hospital Research Institute in Łódź, Poland \\ ${ }^{7}$ Department of Neonatology, Institute of Mother and Child, Warszawa, Poland \\ ${ }^{8}$ Department of Biostatistics, School of Public Health in Bytom, Medical University of Silesia, Poland \\ ${ }^{9}$ Department of Pediatrics, Division of Propedeutic Pediatrics and Rare Disorders, Wroclaw Medical University, Poland \\ A - research concept and design; $B$ - collection and/or assembly of data; $C$ - data analysis and interpretation; \\ $D$ - writing the article; $E$ - critical revision of the article; $F$ - final approval of the article
}

\section{Address for correspondence}

Wojciech Walas

E-mail:wojciechwalas@wp.pl

Funding sources

None declared

Conflict of interest

None declared

Received on June 10, 2020

Reviewed on June 30, 2020

Accepted on August 11, 2020

Published online on September 16, 2020

Cite as

Walas W, Halaba Z, Kubiaczyk A, et al. Skin conductance measurement for the assessment of analgosedation adequacy in infants treated with mechanical ventilation: A multicenter pilot study. Adv Clin Exp Med. 2020;29(9): 1117-1121. doi:10.17219/acem/126286

D0I

10.17219/acem/126286

Copyright

Copyright by Author(s)

This is an article distributed under the terms of the

Creative Commons Attribution 3.0 Unported (CC BY 3.0)

(https://creativecommons.org/licenses/by/3.0/)

\begin{abstract}
Background. Patients treated in neonata//pediatric intensive care units (N/PICUs) are frequently exposed to pain. To assess its severity, several behavioral and behavioral-physiological scales are used, but their usefulness is limited. It is therefore justified to search for additional methods to assess the adequacy of analgesia and sedation in these patients.
\end{abstract}

Objectives. To evaluate the usefulness of skin conductance (SC) measurement in the assessment of analgosedation quality in infants requiring mechanical ventilation treated in N/PICUs.

Material and methods. Thirty infants aged $6-208$ days treated in $6 \mathrm{~N} / P$ PICUs, mechanically ventilated and receiving analgosedation, were included for the study. Simultaneous COMFORT-B assessment and SC measurement using SCA (skin conductance algesimeter) monitor were performed. Due to technical problems, not all of the SC records could be interpreted, and finally 412 simultaneous assessments on the COMFORT-B scale and SC measurements in 29 patients were analyzed.

Results. We found a statistically significant correlation between the COMFORT-B scoring and the SC measurements. Additionally, SC was significantly lower when the behavioral score indicated deep sedation, in comparison to periods when it indicated moderate or insufficient analgosedation.

Conclusions. Skin conductance measurements are comparable with the COMFORT-B rating in mechanically ventilated infants receiving analgosedation. The SCA monitor may be of value in the assessment of analgosedation quality, and in particular may identify the situation where sedation is deep. Further research is needed regarding the suitability of this device in clinical practice.

Key words: pain, analgosedation, infant, skin conductance, COMFORT-B scale 


\section{Introduction}

As defined by the International Association for the Study of Pain, pain is an unpleasant sensory and emotional experience associated with actual or potential tissue damage, or described in terms of such damage. ${ }^{1}$ It is understandable that patients treated in neonatal/pediatric intensive care units (N/PICUs) are exposed to pain. Newborns and infants may suffer both from illness, particularly after surgery, and from chronic use of the procedures causing discomfort, such as tracheal intubation, as well as experience additional procedural pain. This also applies to patients in analgosedation. Insufficient pain control is harmful not only from an ethical point of view, but also because of adverse development consequences. ${ }^{2-4}$ On the other hand, the extensive use of sedation and analgesia may also cause side effects and disrupt neurological development. ${ }^{5-8}$ For successful pain management, it is necessary to assess its occurrence and severity, which is difficult in newborns and infants due to the lack of verbal communication. In patients treated in N/PICU, behavioral and behavioralphysiological scales are used to assess pain. However, all these scales have disadvantages and limitations. Their use requires considerable staff involvement, is time consuming and the assessment is always more or less subjective. In addition, the assessment is intermittent and performed at intervals, and therefore there is a risk of overlooking pain episodes. For this reason, although pain should be considered a "fifth vital parameter", the protection against pain is often unsatisfactory among N/PICU patients. ${ }^{9-13}$ It is therefore understandable that additional objective pain assessment methods are constantly being sought. Of the various solutions, methods based on measurement electrical skin conductance (SC) are promising. Our goal was to assess the usefulness of Skin Conductance Algesimeter (SCA; MedStorm Innovation, Oslo, Norway) in the assessment of pain in mechanically ventilated infants receiving analgosedation by comparing the measurements with the scoring on the behavioral (COMFORT-B) scale.

This was a prospective observational study, which did not require any changes from the standard treatment of included patients. The acceptance of the local ethical committee was granted (approval No. 270 from October 11, 2018).

\section{Material and methods}

\section{Patients}

We enrolled 30 neonates and infants treated in N/PICUs. Inclusion criteria were as follows: gestational age at birth over 26 weeks and chronological age less than 1 year, mechanical ventilation through an endotracheal tube, and analgosedation (fentanyl/midazolam). Exclusion criteria included: bradycardia $<80 \mathrm{bpm}$, tachycardia $>250 \mathrm{bpm}$, any cardiac rhythm other than sinus one, use of medication that have effects on sympathetic and parasympathetic activity (e.g., beta blockers) during a period of 7 days before the study, intraventricular hemorrhage of IV degree, severe perinatal asphyxia treated by therapeutic hypothermia, central nervous system congenital malformations, seizures in the 7 days preceding the study and neuromuscular diseases, and analgosedation other than fentanyl/midazolam. All parents/legal guardians were given an information form and gave their approval for the study.

\section{Study protocol}

The fentanyl/midazolam analgosedation was carried out in accordance with the rules used by the participating departments and the study did not affect it. Patients were constantly monitored using a SCA monitor. They were also periodically evaluated using the COMFORT-B scale. The intervals between the COMFORT-B scoring were at least $1 \mathrm{~h}$. Patients were not disturbed by any additional procedures during the 15-minute period before this assessment.

\section{Pain assessment}

The COMFORT-B scale is dedicated for mechanically ventilated patients and is used to assess the degree of analgosedation. ${ }^{14}$ The scale consists of 6 behavioral items: alertness, calmness, respiratory response, body movements, facial tension, and muscle tone. A scale from 1 point (the highest) to 5 points (the lowest) sedation level is assigned to each variable. The minimum and maximum of total scores is 6 and 30 , respectively. Scores 6-10 indicate deep analgosedation, scores 11-23 indicate a moderately sedated patient and scores $>23$ indicate insufficient sedation. COMFORT-B assessment was performed by experienced neonatologists who did not have access to the measurements presented by the SCA monitor.

The SCA monitor works based on the analysis of SC changes in response to pain stimuli. Skin conductance activity reflects the sympathetic nervous system activity influenced by changes in emotions, releasing acetylcholine that acts on muscarine receptors and causes a subsequent burst of sweat and variations in ions secretion. The measurement is performed using 3 self-adhesive electrodes attached to palmar or plantar skin. A comprehensive description of the SC methodology has been published by Storm. ${ }^{15,16}$ The SCA device displays several parameters, of which, according to the manufacturer's recommendations and the data from literature, peaks per second (PPS) parameter was chosen as the most suitable for assessing pain in preterm and term infants under analgosedation. ${ }^{17,18}$ Recommended window of $15 \mathrm{~s}$ was used for analysis. A higher level of PPS corresponds to a stronger pain sensation. 


\section{Statistical analysis}

We analyzed the correlation of the COMFORT-B scoring and the PPS levels using Spearman's correlation coefficient. We compared also the PPS levels using Mann-Whitney $\mathrm{U}$ test in the subgroups identified based on the COMFORT-B rating. We assumed the significance level $\mathrm{p}<0.05$. The SAS software v. 9.4 (SAS Institute Inc., Cary, USA) was used for statistical analysis.

\section{Results}

Thirty patients were included, in whom an assessment using COMFORT-B scale was performed 442 times. The 30 SCA records (7\% of all) were illegible for assessment due to artifacts (in 1 patient all records) and were excluded. In the final analysis, 412 simultaneous assessments on the COMFORT-B scale and PPS levels in 29 patients were analyzed. The details of patients are presented in Table 1. There was statistically significant correlation of the COMFORT-B scale and PPS levels with coefficient 0.279 ( $\mathrm{p}<0.0001$ ). The COMFORT-B rating $\leq 10$ (deep analgosedation) was measured in 324 cases (79\%), 11-23 (moderate analgosedation) in 86 cases $(20.5 \%)$ and $>23$ (insufficient analgosedation) in 2 cases $(0.5 \%)$. Small number of events when COMFORT-B scores were $>23$ did not allow a comparison of the PPS levels in situations when the analgosedation was moderate and when was insufficient. Therefore, we compared PPS levels between deep and moderate/insufficient subgroups. The PPS levels were significantly lower in the deep analgosedation subgroup (median: 0.00) than in the moderate/insufficient analgosedation subgroup (median: 0.04) ( $\mathrm{p}<0.001$ ). Nine data points in the deep analgosedation subgroup (2.7\%) and 6 in the moderate/insufficient analgosedation subgroup (6.8\%) have differed significantly from other observations and were considered outliers. The results are shown in Fig. 1.

Table 1. Characteristics of the studied group

\begin{tabular}{|c|c|}
\hline $\begin{array}{l}\text { Overall characteristics } \\
\qquad(\mathrm{n}=29)\end{array}$ & $\begin{array}{c}\text { Mean } \pm \text { SD }\left(\min -\max ^{*}\right) \\
\text { median }\left(1^{\text {st }}-3^{\text {rd }} \text { quartile }\right) \\
\left(\min -\max ^{* *}\right)\end{array}$ \\
\hline Gestational age [weeks] & $34 \pm 4.5\left(25-40^{*}\right)$ \\
\hline Birthweight [g] & $2408 \pm 1036\left(560-4200^{*}\right)$ \\
\hline Females/males & $14(48 \%) / 15(52 \%)$ \\
\hline $\begin{array}{l}\text { Characteristics at the time } \\
\text { of the events } \\
(n=412)\end{array}$ & $\begin{array}{l}\text { Mean } \pm \text { SD }\left(\min -\max ^{*}\right) \\
\text { median }\left(1^{\text {st }}-3^{\text {rd }} \text { quartile }\right) \\
\left.\text { (min- } \max ^{* *}\right)\end{array}$ \\
\hline Age [days] & $6(4-23)\left(1-208^{* *}\right)$ \\
\hline Postmenstrual age [weeks] & $38(35-41)\left(26-55^{* *}\right)$ \\
\hline Weight [g] & $3600(2975-3800)\left(865-5800^{* *}\right)$ \\
\hline
\end{tabular}

* normal distribution; ** non-normal distribution according

to the Shapiro-Wilk test; SD - standard deviation.

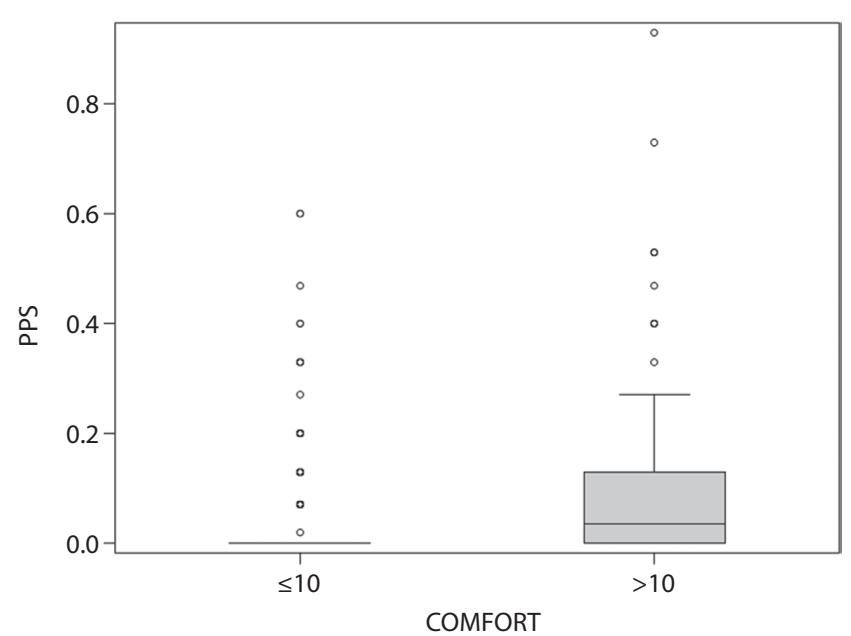

Fig. 1. SCA levels (PPS) depending on the assessment of analgosedation using the COMFORT-B scale (deep compared to moderate/insufficient)

\section{Discussion}

Our study included a specific group of patients: neonates and infants mechanically ventilated and receiving analgosedation. We found a statistically significant correlation between the COMFORT-B score and PPS levels. From a clinical point of view, the quality of analgosedation is of utmost importance. For this reason, we set thresholds based on a behavioral scale. We found that PPS levels are significantly lower in situations where the COMFORT-B rating indicates profound analgosedation compared to situations where this assessment indicates that analgosedation is moderate or insufficient. The identification of patients with deep analgosedation seems to be important considering its adverse consequences.

Skin conductance measurements have been shown to be useful in assessing pain in patients of different age groups and in different clinical situations. Some of the research comprises neonates, infants and children, the vast majority concerning only the assessment of procedural pain. Storm, Scaramuzzo et al., Eriksson et al., Pereira-da-Silva et al., de Jesus at al., as well as Tristão et al. have shown that at-term neonates SC increases in response to pain stimuli. ${ }^{15,17-23}$ Munsters et al. and Macko et al. have shown the same reaction in preterm neonates. ${ }^{24,25}$ Zeiner at al., Hellerud et al., Lyngstad et al., and Salavitabar et al. noted that SC changes in response to various forms of handling, sensory stimulation, mother and newborn skin-to skin contact and sound stimuli. ${ }^{26-29}$ Only a few studies focus on assessing the usefulness of SCA in evaluating the severity of pain and the effectiveness of analgosedation in infants and children in the postoperative period and/or treated in N/PICU. Gjerstad et al. obtained results similar to ours. They examined the correlation between SC, COMFORT score, heart rate, and arterial blood pressure during endotracheal suctioning in a group of 20 mechanically ventilated patients, including neonates. They noted that the PPS showed better 
correlation with the increase in the COMFORT score than heart rate and arterial blood pressure. They concluded that for monitoring of stress in artificially ventilated children, SCA seems to be an objective supplement to the behavioral scoring. ${ }^{30}$ Hullet et al. assessed pain intensity in the postoperative period in 180 children aged $1-16$ years using SC analysis and various 3 behavioral scales depending on the patient's age. They concluded that PPS may play an important role in the assessment of pediatric pain, especially when used as a predictor of moderate/severe pain. ${ }^{31}$ The usefulness of SC monitoring in the assessment of pain in mechanically ventilated neonates was also studied by Karpe et al. They analyzed SC fluctuations during tracheal suctioning and heel stick in term and near-term neonates under analgosedation. They noted a significant increase in SC levels in response to pain stimuli; however, they did not compare this reaction with other pain assessment methods. They concluded that changes of SC level demonstrate that, despite sedation and analgesia, neonates experience discomfort related to the therapeutic and diagnostic procedures. ${ }^{32}$ On the contrary, results of research done by Solana et al. in 61 mechanically ventilated critically ill children aged from 1 month to 16 years and receiving analgosedation showed that, although the PPS increased significantly during the painful procedures, it never reached the level considered diagnostic for pain or stress. The authors concluded that SC is no more sensitive or faster than clinical scales for the assessment of pain or stress in critical children undergoing painful procedures. ${ }^{33}$ Van der Lee et al. performed a study in which they evaluated PPS in response to tracheal intubation in neonates receiving different types of premedication. They concluded that the variation in SC measurements between individual neonates limits the usefulness of PPS as stress monitor during intubation and the use of neuromuscular blockers for premedication precludes monitoring of PPS in neonates. ${ }^{34}$ Also, Choo et al. based on research of 90 school-age children noted that PPS measurement is feasible in a perioperative setting but was not specific for postoperative pain intensity and was unable to identify analgesia requirements when compared with self-report measures. ${ }^{35}$ The results of research performed by Dalal et al. in 34 infants aged 6-12 months in the postoperative period are less obvious. The authors assessed pain intensity on the NFCS scale and simultaneously measured various SC parameters. They found that SCA may be useful in assessing infant pain, but noticed that that the peak amplitude of the SC values may be a better indicator of pain scores than the PPS. ${ }^{36}$ Ledowski, on the basis of a review of the literature on instrumental pain monitoring, came to the conclusion that there is currently no evidence for a clinically relevant benefit arising from the perioperative utilization of SC monitoring. ${ }^{37}$

Our study has a significant limitation: too few COMFORT-B scores $>23$ prevented the assessment of the usefulness of the monitor in identifying situations when analgosedation is insufficient. Nevertheless, we believe that the ability to identify the deep analgosedation using SCA is valuable from a clinical point of view, especially in the context of avoiding side effects of oversedation.

\section{Conclusions}

Skin conductance measurements are comparable with the COMFORT-B rating in mechanically ventilated infants receiving analgosedation. The SCA monitor may be of value in the assessment of analgosedation quality, and in particular may identify the situation where sedation is deep. Further research is needed regarding the suitability of this device in clinical practice.

\section{ORCID iDs}

Wojciech Walas (D) https://orcid.org/0000-0001-7941-2718 Zenon Halaba (D) https://orcid.org/0000-0002-2905-0437 Agata Kubiaczyk (D) https://orcid.org/0000-0002-2725-564X Andrzej Piotrowski (D) https://orcid.org/0000-0002-1585-1815 Julita Latka-Grot (10) https://orcid.org/0000-0002-0442-4199 Tomasz Szczapa (D) https://orcid.org/0000-0002-5214-2719 Monika Romul (D) https://orcid.org/0000-0003-4728-1594 Iwona Maroszyńska (iD https://orcid.org/0000-0003-4061-4843 Ewelina Malinowska (D) https://orcid.org/0000-0001-8922-1819 Magdalena Rutkowska (1) https://orcid.org/0000-0002-4503-2829 Michał Skrzypek (D) https://orcid.org/0000-0003-3410-7407 Robert Śmigiel (D) https://orcid.org/0000-0003-2930-9549

\section{References}

1. International Association for the Study of Pain. https://www.iasppain.org/Education/Content.aspx?ItemNumber=1698\#Pain. Accessed June 17, 2020.

2. Vinall J, Grunau RE. Impact of repeated procedural pain-related stress in infants born very preterm. Pediatr Res. 2014;75(5):584-587.

3. Ranger M, Grunau RE. Early repetitive pain in preterm infants in relation to the developing brain. Pain Manag. 2014;4(1):57-67.

4. Duerden EG, Grunau RE, Guo T, et al. Early procedural pain is associated with regionally-specific alterations in thalamic development in preterm neonates. J Neurosci. 2018;38(4):878-886.

5. Kesavan K. Neurodevelopmental implications of neonatal pain and morphine exposure. Pediatr Ann. 2015;44(11):e260-e264.

6. McPherson C, Haslam M, Pineda R, Rogers C, Neil JJ, Inder TE. Brain injury and development in preterm infants exposed to fentanyl. Ann Pharmacother. 2015;49(12):1291-1297. doi:10.1177/1060028015606732

7. Duerden EG, Guo T, Dodbiba L, et al. Midazolam dose correlates with abnormal hippocampal growth and neurodevelopmental outcome in preterm infants. Ann Neurol. 2016;79(4):548-559.

8. Schiller RM, Allegaert $K$, Hunfeld M, van den Bosch GE, van den Anker J, Tibboel D. Analgesics and sedatives in critically ill newborns and infants: The impact on long-term neurodevelopment. J Clin Pharmacol. 2018;58(Suppl 10):S140-S150. doi:10.1002/jcph.1139

9. Avila-Alvarez A, Carbajal R, Courtois E, Pertega-Diaz S, Anand KJ, Muñiz-Garcia J; Grupo español del proyecto Europain. Clinical assessment of pain in Spanish neonatal intensive care units [in Spanish]. An Pediatr (Barc). 2016;85(4):181-188.

10. Courtois E, Droutman S, Magny JF, et al. Epidemiology and neonatal pain management of heelsticks in intensive care units: EPIPPAIN 2, a prospective observational study. Int J Nurs Stud. 2016;59:79-88.

11. Sposito NPB, Rossato LM, Bueno M, Kimura AF, Costa T, Guedes DMB. Assessment and management of pain in newborns hospitalized in a neonatal intensive care unit: A cross-sectional study. Rev Lat Am Enfermagem. 2017;12;25:e2931. doi:10.1590/1518-8345.1665.2931

12. Lago $P$, Frigo AC, Baraldi $E$, et al. Sedation and analgesia practices at Italian neonatal intensive care units: Results from the EUROPAIN study. Ital J Pediatr. 2017;43:26 
13. Anand KJS, Eriksson M, Boyle EM, Avila-Alvarez A, Andersen RD, Sarafidis K; EUROPAIN Survey Working Group of the NeoOpioid Consortium. Assessment of continuous pain in newborns admitted to NICUs in 18European countries. Acta Paediatr. 2017;106(8):1248-1259.

14. Ista $E$, van Dijk M, Tibboel D, de Hoog M. Assessment of sedation levels in pediatric intensive care patients can be improved by using the COMFORT "behavior" scale. Pediatr Crit Care Med. 2005;6(1):58-63.

15. Storm $\mathrm{H}$. Skin conductance and the stress response from heel stick in preterm infants. Arch Dis Child Fetal Neonatal Ed. 2000; 83(2):F143-F147.

16. Storm $\mathrm{H}$. The development of a software program for analyzing skin conductance changes in preterm infants. Clin Neurophysiol. 2001; 112(8):1562-1568.

17. Storm H. Changes in skin conductance as a tool to monitor nociceptive stimulation and pain. Curr Opin Anaesthesiol. 2008;21(6):796-804.

18. Storm H. Pain monitoring in anesthetized children: First assessment of skin conductance and analgesia-nociception index at different infusion rates of remifentanil. Recommended preset values for the skin conductance equipment was not used. Paediatr Anaesth. 2013;23(8):761-763.

19. Scaramuzzo RT, Faraoni M, Polica E, Pagani V, Vagli E, Boldrini A. Skin conductance variations compared to $A B C$ scale for pain evaluation in newborns. J Matern Fetal Neonatal Med. 2013;26(14):1399-1403.

20. Eriksson M, Storm H, Fremming A, Schollin J. Skin conductance compared to a combined behavioural and physiological pain measure in newborn infants. Acta Paediatr. 2008,97(1):27-30.

21. Pereira-da-Silva L, Virella D, Monteiro I, et al. Skin conductance indices discriminate nociceptive responses to acute stimuli from different heel prick procedures in infants. J Matern Fetal Neonatal Med. 2012;25(6):796-801.

22. de Jesus JA, Campos D, Storm H, da Rocha AF Tristão RM. Skin conductance and behavioral pain scales in newborn infants. Psychol Neurosci. 2015;8(2):203-210.

23. Tristão RM, Garcia NV, de Jesus JA, Tomaz C. COMFORT behaviour scale and skin conductance activity: What are they really measuring? Acta Paediatr. 2013;102(9):e402-e406.

24. Munsters J, Wallström L, Agren J, Norsted T, Sindelar R. Skin conductance measurements as pain assessment in newborn infants born at 22-27 weeks gestationalage at different postnatalage. EarlyHum Dev. 2012;88(1):21-26.

25. Macko J, Moravcikova D, Kantor L, Kotikova M, Humpolicek P. Skin conductance as a marker of pain in infants of different gestational age. Biomed Pap Med Fac Univ Palacky Olomouc Czech Repub. 2014;158(4): 591-595.
26. Zeiner V, Storm H, Doheny KK. Preterm infants' behaviors and skin conductance responses to nurse handling in the NICU.J Matern Fetal Neonatal Med. 2016;29(15):2531-2536.

27. Hellerud BC, Storm H. Skin conductance and behavior during sensory stimulation of preterm and term infants. Early Hum Dev. 2002;70 (1-2):35-46

28. Lyngstad LT, Tandberg BS, Storm H, Ekeberg BL, Moen A. Does skin-toskin contact reduce stress during diaper change in preterm infants? Early Hum Dev. 2014;90(4):169-172.

29. Salavitabar A, Haidet KK, Adkins CS, Susman EJ, Palmer C, Storm H. Preterm infants' sympathetic arousal and associated behavioral responses to sound stimuli in the neonatal intensive care unit. Adv Neonatal Care. 2010;10(3):158-166.

30. Gjerstad AC, Wagner K, Henrichsen T, Storm H. Skin conductance versus the modified COMFORT sedation score as a measure of discomfort in artificially ventilated children. Pediatrics. 2008;122(4):e848-e853.

31. Hullett B, Chambers N, Preuss J, et al. Monitoring electrical skin conductance: A tool for the assessment of postoperative pain in children? Anesthesiology. 2009;111(3):513-517.

32. Karpe J, Misiołek A, Daszkiewicz A, Misiołek H. Objective assessment of pain-related stress in mechanically ventilated newborns based on skin conductance fluctuations. Anaesthesiol Intensive Ther. 2013;45(3):134-137.

33. Solana MJ, Lopez-Herce J, Fernandez S, et al. Assessment of pain in critically ill children: Is cutaneous conductance a reliable tool? J Crit Care. 2015;30(3):481-485.

34. van der Lee $R$, Jebbink LJ, van Herpen TH, d'Haens EJ, Bierhuizen J van Lingen RA. Feasibility of monitoring stress using skin conduction measurements during intubation of newborns. Eur J Pediatr. 2016;175(2):237-243.

35. Choo EK, Magruder W, Montgomery CJ, Lim J, Brant R, Ansermino JM. Skin conductance fluctuations correlate poorly with postoperative self-report pain measures in school-aged children. Anesthesiology. 2010;113(1):175-182.

36. Dalal PG, Doheny KK, Klick L, et al. Analysis of acute pain scores and skin conductance measurements in infants. Early Hum Dev. 2013; 89(3):153-158.

37. Ledowski T. Objective monitoring of nociception: A review of current commercial solutions. Br J Anaesth. 2019;123(2):e312-e321. 